\title{
Humanização das Práticas de Cuidado em Saúde Mental: Perspectiva dos Usuários Acerca do Cuidado Ofertado por Duas Unidades de Saúde da Família
}

\author{
Frateschi, Mara Soares; Cardoso, Carmen Lúcia \\ Faculdade de Filosofia Ciências e Letras de Ribeirão Preto - Universidade de São Paulo - \\ msfrateschi@hotmail.com
}

Introdução: a Estratégia Saúde da Família (ESF) tem se destacado como uma importante alternativa para a $(r e)$ inserção da pessoa em sofrimento mental na sociedade, em conformidade com os preceitos da Reforma Psiquiátrica. Neste contexto, as políticas de Humanização estão diretamente relacionadas ao processo de desinstitucionalização da assistência psiquiátrica, investindo no cuidado de base territorial e na valorização da pluralidade que compõe as pessoas, as comunidades e as relações. Assim, torna-se importante reconhecer o usuário como protagonista do sistema de saúde, com capacidade de se posicionar, avaliando e intervindo, diante do cuidado que recebe. Objetivo: Identificar e compreender os sentidos atribuídos pelos usuários da ESF às práticas de cuidado em saúde mental das quais dispõem. Métodos: Foram realizadas entrevistas abertas e individuais a cinco usuários que recorrem a Unidades de Saúde da Família (USF) com queixas de sofrimento mental. o trabalho foi realizado em duas USF. As entrevistas foram audiogravadas e transcritas. o material foi submetido à análise seguindo a abordagem qualitativa e utilizou-se como ferramenta a Análise de Conteúdo. Resultados: a partir da análise do material, os resultados foram dispostos em quatro categorias que remetem a diferentes aspectos do cuidado. a categoria "Demanda" aborda os motivos pelos quais os usuários buscaram o serviço, o que inclui queixas de tristeza, solidão, variação de humor, sobrecarga de tarefas, conflitos familiares. a categoria "Ações" aborda as alternativas de cuidado ofertadas pelas USF. As ações citadas foram: consulta médica, atendimento psiquiátrico, tratamento medicamentoso, psicoterapia e encaminhamento para serviços especializados. a categoria "Dificuldades" se refere às queixas dos usuários quanto à assistência recebida. As queixas foram: Necessidade de explorar alternativas não medicamentosas e falta de profissionais qualificados para uma escuta atenta e transformadora. a categoria "Sugestões" aborda as propostas de melhorias do cuidado, o que inclui a consolidação de espaços de convivência, maior oferta de profissionais especializados, maior disponibilidade dos profissionais para ouvir. Conclusões: Os usuários se posicionaram diante de sua saúde e de suas condições de vida, manifestando-se criticamente sobre a assistência em saúde mental que recebem. Apesar de identificarem o cuidado recebido como sendo de ajuda, apontaram para a necessidade de serem consolidados espaços de convivência e troca entre a comunidade e a equipe, bem como de serem exploradas estratégias que transcendam a lógica medicamentosa, considerando-se os recursos existentes no território e na rede de apoio de cada pessoa. As informações dos usuários, por carregarem conteúdos individuais e coletivos, perpassados por fatores econômicos, sociais, políticos e culturais, constituem peças-chave para a consolidação de novas formas de pensar e agir em saúde, mais humanas e universais. (Financiamento: FAPESP)

Frateschi, Mara Soares; Cardoso, Carmen Lúcia. Humanização das Práticas de Cuidado em Saúde Mental: Perspectiva dos Usuários Acerca do Cuidado Ofertado por Duas Unidades de Saúde da Família.. In: Anais do Congresso Internacional de Humanidades \& Humanização em Saúde [= Blucher Medical Proceedings, num.2, vol.1]. São Paulo: Editora Blucher, 2014. ISSN 2357-7282

DOI 10.5151/medpro-cihhs-10629 